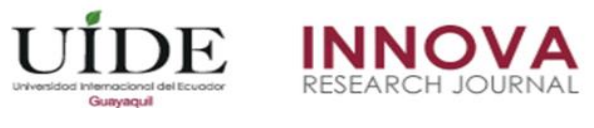

INNOVA Research Journal, ISSN 2477-9024

(Enero, 2017). Vol. 2, No.1 pp.14-33

DOI: https://doi.org/10.33890/innova.v2.n1.2017.103

URL: http://revistas.uide.edu.ec/index.php/innova/index

Correo: innova@uide.edu.ec

\title{
Emprendimientos productivos de souvenirs y artesanías con enfoque de lojanidad e identidad ancestral
}

\section{Productive undertakings of souvenirs and handicrafts with focus on loranity and ancestral identity}

Jeamil Burneo Villamagua

Universidad Internacional del Ecuador, Ecuador

Autor para correspondencia: jeburneosa@internacional.edu.ec

Fecha de recepción: 28 de Octubre de 2016 - Fecha de aceptación: 20 de Diciembre de 2016.

Resumen: El proyecto de investigación nace analizando las potencialidades que tiene el diseño con identidad para generar un producto cultural que sea representativo de un territorio. Los pueblos ancestrales ecuatorianos produjeron en el pasado aborigen, e incluso mantuvieron y recrearon hasta el presente un importante patrimonio cultural que constituye la producción identitaria más profunda lograda en el país. Este patrimonio, particularmente las representaciones iconográficas, tienen la enorme potencialidad de convertirse en la base para una creación original, coherente, de alto valor cultural y estético. Lastimosamente no se realizado un proceso de sistematización y en la actualidad es incipiente la producción artesanal que presenten una investigación rigurosa para transmitir la cultura y cosmovisión originarias. Dentro del evento lo hemos considerado en la línea de Innovación en los emprendimientos y las MIPyME. Igualmente percibimos una falencia al desarrollar productos de difusión gráfica que representen la cultura de un territorio, la cual se puede plasmar en souvenir turísticos con identidad, la idea es además revitalizar la cultura con nuevos iconos nuevos a ser aplicados en objetos (artesanías), en la arquitectura local y el urbanismo. Al describir estos sustentos iconográficos y simbólicos se posibilita la actividad creativa con lenguaje artístico nuevo pero con raíces culturales e históricas, buscando la transferencia de la memoria histórica, para así crear identidad cultural, incentivando el turismo, la cultura, y por ende el desarrollo local y regional. Precisamente el proyecto aporta con la creación de patrones gráficos, se generan prototipos de diseño, posibilitando su futura producción semindustrial de ellos. La incorporación de los saberes ancestrales y la identidad para crear patrones de diseño contemporáneo que puede ser expresado en producción de productos en diferentes gamas artesanales que permita que pequeños emprendimientos produzcan de manera adecuada.

Palabras claves: Investigación; vinculación con la comunidad; fenomenología; iconografía; iconología

Abstract: The research project is born analyzing the potential that has the design identity to generate
a cultural product that is representative of a territory. Ecuadorian ancestral Aboriginal peoples occurred
in the past, and even maintained and recreated to present an important cultural heritage that is the
deepest identity production achieved in the country. This heritage, particularly the iconographic
representations, have enormous potential to become the basis for an original, coherent, creating high
cultural and aesthetic value. Unfortunately not a systematization process is done and now is emerging
handicraft production to submit a thorough investigation to transmit culture and worldview originating.
In the event we have seen in the line of innovation in entrepreneurship and MIPyME. Likewise we 
perceive a flaw in developing products graphical distribution representing the culture of a territory, which can be translated into tourist souvenir with identity, the idea is also to revitalize the culture with fresh new icons to be applied to objects (handicrafts), in local architecture and urbanism. In describing these iconographic and symbolic underpinnings creative activity with new artistic language but with cultural and historical roots it is possible, seeking the transfer of historical memory, thus creating cultural identity, encouraging tourism, culture, and thus local development and regional. Precisely the project contributes to creating graphic patterns, design prototypes are generated, enabling future production semindustrial them. The incorporation of ancestral knowledge and identity to create contemporary design patterns that can be expressed in the production of craft products in different ranges that allow small businesses produce properly.

Key Words: Research; links with the community; phenomenology; iconography; iconology

\section{Introducción}

Esta investigación nace desde la Academia, con la finalidad de aplicar el ciclo de incidencia del proceso enseñanza aprendizaje hacia algunos actores necesarios, como son los estudiantes, los profesores, la comunidad y en este caso, de manera específica los artesanos de la provincia de Loja. Esta intencionalidad subyace en la estructura conceptual del CipArq (escuela de arquitectura) de la Universidad Internacional del Ecuador en su extensión Loja (UIDE L), en cuyo caso se plantean 3 componentes que actúan de una manera complementaria y sistémica, los cuales son el ámbito académico, la investigación y la vinculación con la comunidad.

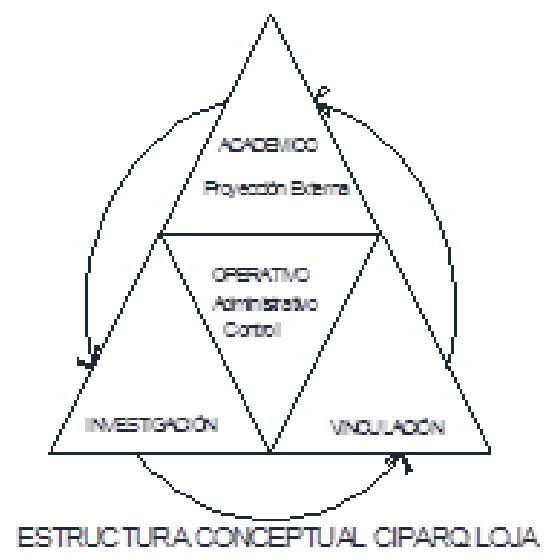

Figura Nro. 1: Proceso articulador de los componentes de la Academia (Ciparq UIDE L) Elaboración: El autor

Siguiendo esta lógica, el Ciparq, desarrolla la línea investigación que le permitió de inicio a la UIDE por primera vez posicionarse entre los 8 proyectos finalistas del "II Concurso De Reconocimiento A La Investigación Universitaria Estudiantil: Galardones Nacionales 2014" de la SENESCYT en el componente de "Saberes Ancestrales" (Hora, 2014). En primera instancia en el ámbito académico se plantea una la malla curricular que identifica algunas asignaturas que de manera trasversal aportan a la formación integral del Arquitecto de la UIDE, una de ellas es la asignatura de Antropología Cultural Nacional, la cual conjuntamente con las asignaturas de Historia de la Arquitectura aportan al estudiante conocimientos relacionado con la heredad cultural y la identidad local; esta característica sumada a la visión del territorio inmanente en la formación del arquitecto, determinaron el interés en el desarrollo de la fase de 
investigación, que finalmente pretende trasferir las experiencias exitosas del proceso hacia un colectivo en particular de personas que trabajan en el proceso creativo intelectual y manual, como son los diseñadores y artesanos lojanos.

Nuestras culturas originarias poseían un rico lenguaje visual, por lo que éste puede ser implementado en el diseño contemporáneo; estos dos, pueden ser el lazo perfecto para que la academia a través de la investigación, se vincule con la comunidad realizando un diálogo de saberes, actividad que se busca potenciar en el territorio ecuatoriano. A su vez, generando desarrollo económico, mediante la producción de objetos con valor agregado.

El objetivo del proyecto es promover la investigación, apropiación y recreación de la cultura de los pueblos originarios de Loja para la creación de propuestas gráficas enfocadas a potenciar la cultura y el desarrollo local.

Se busca entonces transmitir la memoria histórica cultural a los habitantes de Loja, de la región y el país, a través de productos de diseño, creando una marca local con alto valor estético, funcional y cultural, de igual manera busca la apropiación social del patrimonio cultural, que permita a la academia el relacionamiento adecuado a los artesanos, diseñadores, productores, micro y medianas empresas artesanales, que permita generar mayor valor agregado en sus niveles de producción y comercialización. La pregunta de investigación con la cual nace este proyecto, es ¿la labor de la universidad permite identificar, desarrollar nuevos esquemas gráficos y utilizar la iconografía de las culturas originarias para crear diseños contemporáneos aplicables en la artesanía, arquitectura y urbanismo?

Al describir los sustentos iconográficos y simbólicos de las culturas originarias se posibilita la actividad creativa de lenguajes artísticos nuevos pero con raíces culturales e históricas, buscando así crear fortalecer la identidad cultural, incentivando el turismo, el emprendimiento, la innovación por ende el desarrollo local y regional. Los pueblos ancestrales produjeron en el pasado aborigen, e incluso mantuvieron y recrearon hasta el presente un importante patrimonio cultural que constituye la producción identitaria más profunda lograda en el país. Este patrimonio, particularmente las representaciones iconográficas, tienen la enorme potencialidad de convertirse en la base para una creación original, coherente, de alto valor cultural y estético. Lastimosamente no se realizado un proceso de sistematización y en la actualidad es incipiente la producción artesanal que presenten una investigación rigurosa para transmitir la cultura y cosmovisión originarias.

Precisamente el proyecto pretende aportar con la creación de patrones gráficos, generar prototipos de diseño, posibilitando su futura producción semi-industrial con la colaboración de diversas instituciones e instancias, para la aplicación en el diseño. Está producción semiindustrial busca cumplir el segundo objetivo del plan nacional de buen vivir: "Mejorar las capacidades y potencialidades de la ciudadanía"; ya que el proyecto busca que el conocimiento generado en la academia se integre a los intereses planteados por el Estado ecuatoriano, con el fin de crear desarrollo cultural, fomentando el emprendimiento y brindado capacitación a nuestros artesanos.

\section{Del Concepto A La Iconología}


El sustento conceptual del proyecto, vincula en primera instancia conceptos como fenomenología e iconografía, con el objeto de determinar el punto creativo de partida para generar elementos de diseño relacionados con la percepción subjetiva de las emociones y por otro lado la correlación con elementos iconográficos de las culturas originarias.

La fenomenología, estudia las experiencias de las personas relacionadas a cualquier cosa que puede ser parte de la vida de la persona, todo lo que el ser humano puede ver, pensar, sentir, entender, tocar; puede ser algo que la fenomenología investiga como el ser humano entiende o experimenta alguna cosa. Según Edmund Husserl, es la ciencia que estudia la aproximación de los hechos y el ámbito en que se hace presente esta realidad. Consiste en la búsqueda de la comprensión basada en lo que es obvio sencillamente porque es la realidad percibida. La fenomenología, no presupone nada: ni el sentido común, ni el mundo natural, ni las proposiciones científicas, ni las experiencias psicológicas. Se coloca antes de cualquier creencia y de todo juicio para explorar simplemente lo dado. emociones.

El cometido de la fenomenología es estudiar las esencias de las cosas y la de las

En síntesis, el método fenomenológico, consiste en:

- Examinar todos los contenidos de la conciencia

- Determinar si tales contenidos son reales, ideales, imaginarios, etc.

- Suspender la conciencia fenomenológica, de manera tal que resulta posible atenerse a lo dado en cuanto a tal y describirlo en su pureza. (Montaño, 2008).

En la experiencia de la escuela de arquitectura Ciparq de la UIDE L, en la asignatura de Teoría de la Arquitectura, asesorados por la Arq. Vera Bijelic se desarrolló una aplicación práctica en el diseño de objetos culturales sobre su experiencia en la aplicación de la fenomenología en la Arquitectura, la cual trata sobre cómo, el cuerpo humano experimenta el espacio, a partir de la manera de que el habitante también llamado usuario se refiere al uso del espacio. La interrogante se refiere a "cómo, comprender, diseñar, evaluar estos aspectos cualitativos de arquitectura y finalmente hasta qué punto cuando estoy diseñando me estoy preocupado por el objeto en sí y no por la experiencia de ese objeto que tal vez llega a ser más importante."

En términos generales fenomenología es el estudio interpretativo de la experiencia humana y sobre las actividades cotidianas de la persona, la fenomenología proporciona medios conceptuales y metodológicos para examinar estas dimensiones espaciales y arquitectónicas de la experiencia de la vida humana. Dentro de la fenomenología se hace una distinción fundamental entre espacio físico geométrico y espacio existencial. Esta disciplina entra en el mundo de las investigaciones cualitativas y se refiere que el investigador debe encontrarse con el fenómeno y a partir de esos datos genera nuevos conocimientos, hipótesis y teorías.

Investiga a los aspectos relacionados con experiencias sensoriales y emocionales, además grabar estas experiencias para que la persona pueda interpretarlas, fenomenología nos ofrece estos medios para obtener estos tipos de datos para analizarlos. 
La iconografía puede definirse como la disciplina dedicada al estudio del origen y la elaboración de las imágenes y sus relaciones simbólicas y alegóricas. Cabe resaltar que la noción de iconografía está asociada al concepto de iconología, que es la parte de la semiología y la simbología que se encarga de analizar las denominaciones visuales del arte. La iconología estudia cómo se representan valores y virtudes por medio de figuras de personas. La diferencia entre ambos términos es sutil: mientras que la iconografía hace hincapié en la descripción de las imágenes, la iconología propone un estudio más amplio con clasificaciones y comparaciones.

El historiador y crítico de arte Erwin Panofsky (Studies in Iconology -"Estudios sobre iconología"-, 1939) definía "iconografía" como "la rama de la Historia del Arte que se ocupa del contenido temático o significado de las obras de arte en cuanto algo distinto de su forma"; y estableció un "método iconológico" (Panofsky, 1939), para ello, en tres pasos:

A. Sensorial que es la descripción pre iconográfica, únicamente sensorial.

B. Identificación descriptiva de imágenes, historias y alegorías dentro de una obra, llamado análisis iconográfico.

C. Interpretación de acuerdo con el contexto cultural, social e histórico, denominado análisis iconológico.

Dichos pasos fueron aplicados en el ejercicio universitario mencionado, se ubicó en un cuadro las semejanzas entre simbología correspondiente a 4 culturas con interés en la cobertura geográfica, desde lo general se consideró la cultura egipcia, en lo que respecta al ámbito regional se incluyó la cultura mesoamericana Olmeca, igualmente por su connotación nacional de aportan imágenes de la cultura Mindalae del centro del Ecuador, y finalmente se estudian además en lo local manifestaciones de la cultura Palta. Dicho cuadro en su parte relacionativa, determina la percepción de los estudiantes en la interpretación de las figuras determinadas por ellos mismos, atribuyendo 5 emociones que originalmente fueron seleccionadas por otro grupo de estudiantes de un grupo diferente en el tema de fenomenología y adaptación psicológica de los espacios, cuyos resultados se observan en la Figura $n^{\circ} 2$.

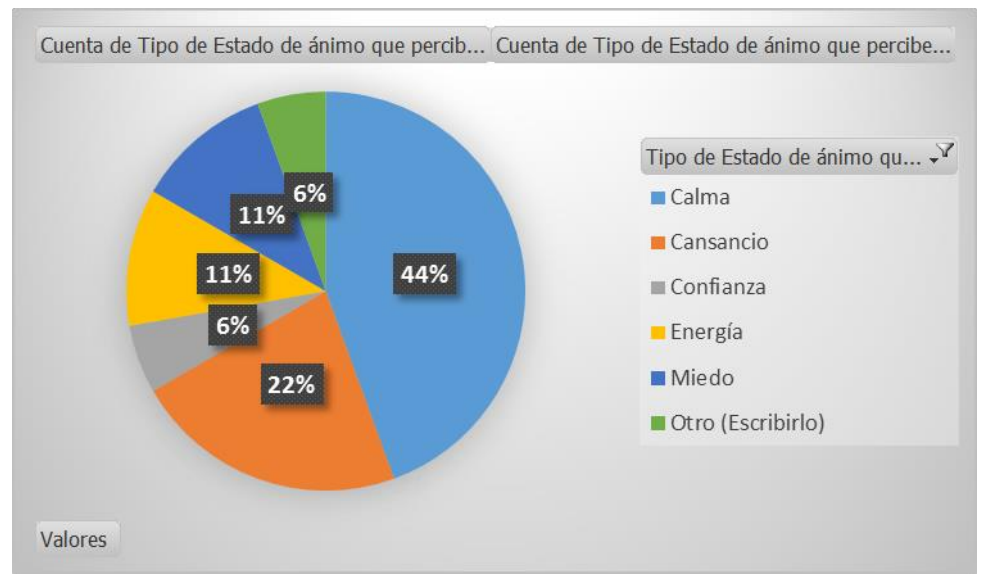

Figura Nro. 2: Emociones percibidas, fenomenología y adaptación psicológica de los espacios. Elaboraron: Estudiantes del Ciparq UIDE. Teoría de la Arquitectura 1 
En dicho estudio además se considera las equivalencias asignadas a los emoticones, que posibilitará encontrar similaridades y semejanzas entre dichas culturas. "Los emoticones son pequeños símbolos, que en el proceso de comunicación, se intercalan entre el mensaje de texto.

En sí mismos tienen un carácter comunicativo, puesto que son códigos utilizados entre emisor y receptor con una significación concreta para ambos. En este caso, con la intención de poder expresar el estado anímico y emocional... esto ha contribuido notablemente a percibir la comunicación en este medio un poco más cercana y humana. Este es un lenguaje específico de la comunicación electrónica (especialmente en el internet, y también en la telefonía móvil). Se ha difundido rápidamente entre los internautas" (Loreto, R. G., \& Toranzo, F. M; 2003).

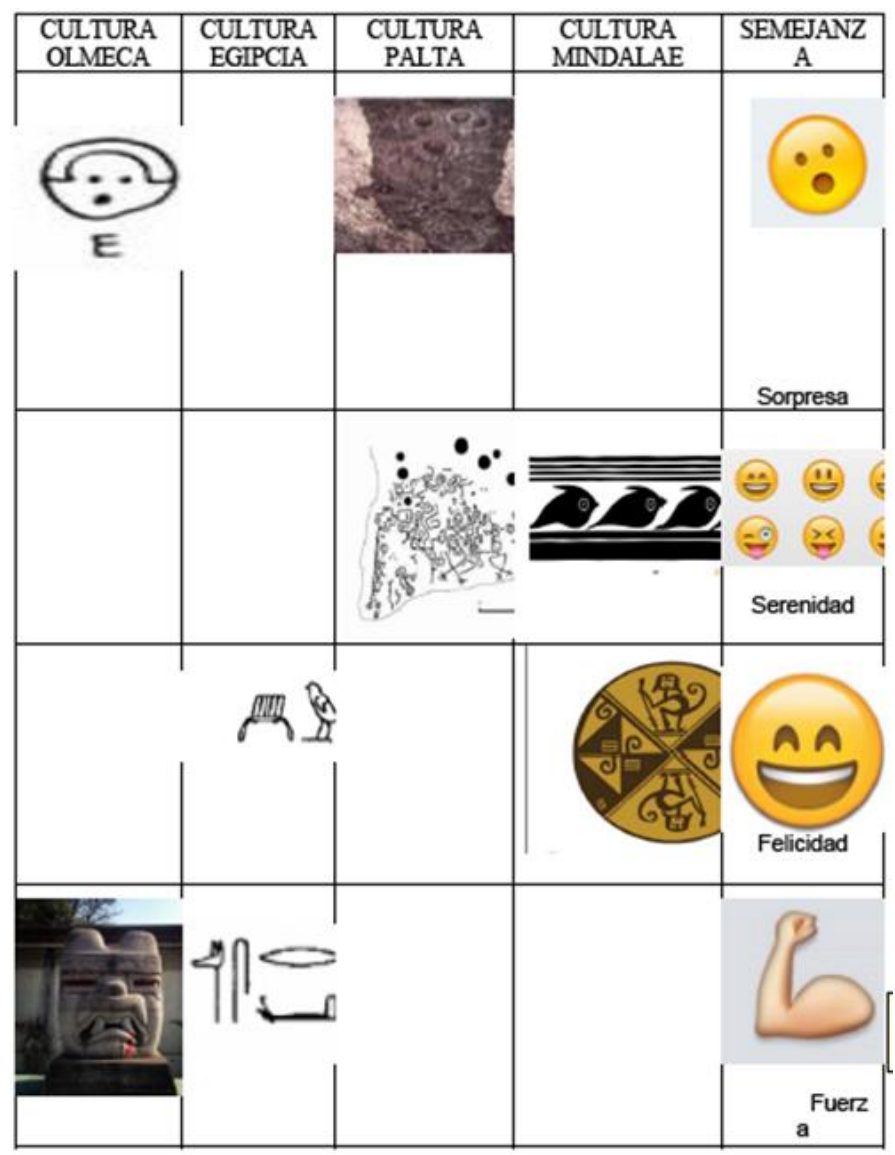



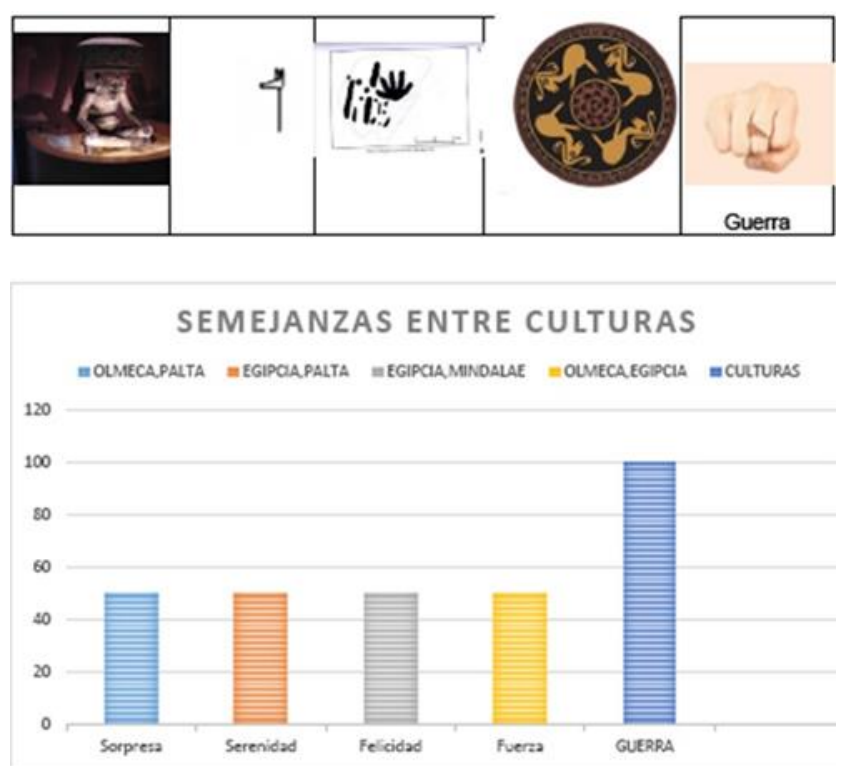

Figura Nro. 3: Semejanzas entre culturas, emoción percibida, desde la relación de la Iconografía y la Fenomenología. Elaboraron: Estudiantes del Ciparq UIDE. Teoría de la Arquitectura 2

Al analizar los datos cualitativos específicos se describen las siguientes conclusiones:

La cultura Olmeca y la cultura Palta tienen una semejanza con el icono de "sorpresa" ya que estas dos culturas se asemejan el mismo rasgo. Aparece en el 50\% de las culturas comparadas.

La cultura Palta y la cultura Mindalae tienen una semejanza con el icono de serenidad ya que estas dos culturas se caracterizan con la armonía y la paz. Aparece en el $50 \%$ de las culturas comparadas.

La cultura egipcia y la cultura Mindalae tienen una semejanza con el icono de felicidad estas culturas se caracterizan por la plenitud y la felicidad y el retorno a un origen. Aparece en el $50 \%$ de las culturas comparadas.

La cultura olmeca y la cultura egipcia tienen una semejanza con el icono de fuerza estas dos culturas se caracterizan por la fuerza y la nobleza del trabajo y el desarrollo de su esfuerzo con su cultura. Aparece en el $50 \%$ de las culturas comparadas.

Este icono, de la guerra se caracteriza con todas las culturas ya que es un esfuerzo entre los hombres para defender a sus pueblos y permitir el desarrollo de cada uno de ellos. Aparece en el $100 \%$ de las culturas comparadas.

De la Iconología e Iconografía, podemos decir que ambos dos vocablos, fueron de común utilización en la cultura griega, procediendo de la misma raíz. 


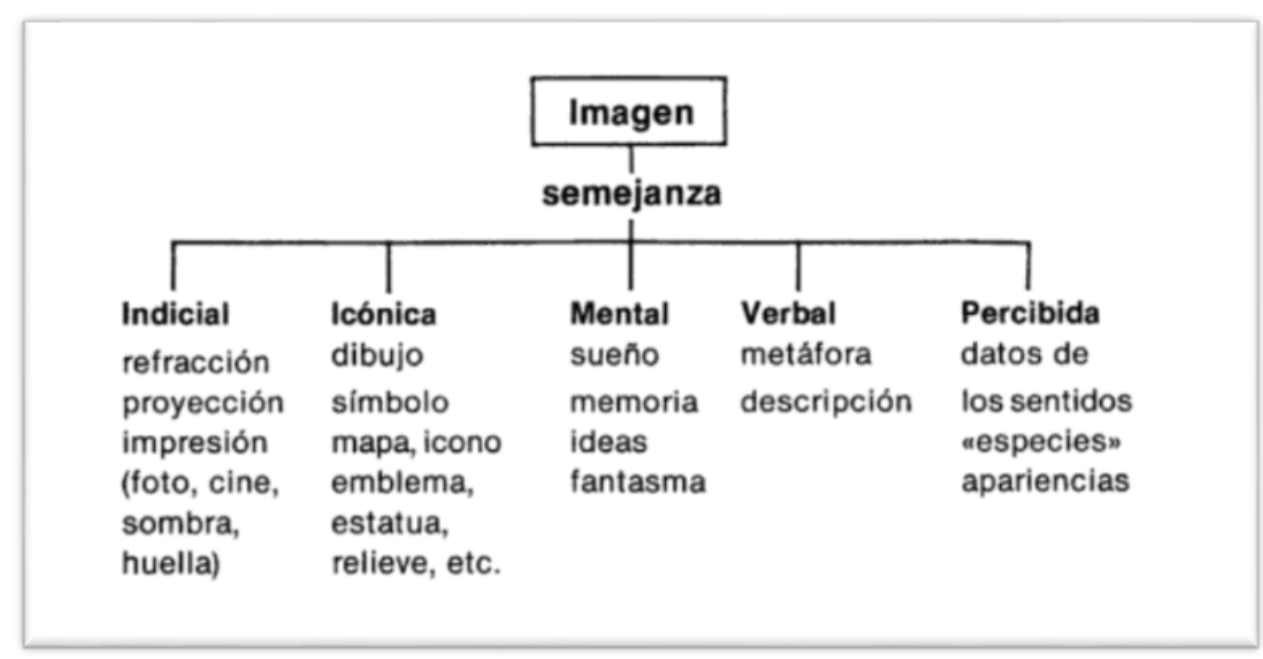

Figura Nro.4: Iconología vs. Iconografía. Fuente: Peltzer Gonzalo

Esta clasificación por los modos de asemejarse la imagen a su significado, va algo más lejos en ella se adelantan la condición analógica de las mismas convenciones y se establece una diferencia entre las imágenes indíciales y las icónicas. Dar al mismo tratamiento a la fotografía que a las imágenes analógicas realizados por el hombre seria como igualar la realidad con la imagen mental. Iconográfico, por tanto puede ser lo visual no fotográfico, ni linguiístico ni paralingüístico, ni la diagramación de las mismas series visuales. (Peltzer Gonzalo).

\section{2. $\quad$ El Proceso De Diseño (Fase 1)}

En esta fase, y con el objeto de aplicar en el diseño de elementos utilitarios, los conceptos preliminares, se aborda como meta la realización de piezas de ajedrez con motivos ancestrales, recabados de la iconología originaria de los pueblos del Ecuador y de la provincia de Loja.

Hemos escogido dicho tema especialmente por las connotaciones globales que subyacen en el entendimiento del famoso juego de salón y de las características simbólicas de cada pieza y su actividad en el tablero.

El ajedrez es un juego de ingenio, para dos jugadores, en el que el azar no interviene en absoluto y que requiere un importante esfuerzo intelectual. Cada jugador dispone de dieciséis piezas. Un jugador juega con las piezas blancas y otro con las negras. Cada grupo de piezas consta de un rey, una reina, dos alfiles, dos caballos, dos torres y ocho peones.

Se juega sobre un tablero dividido en 64 casillas de colores alternados (normalmente blanco y negro). El tablero se coloca ante los jugadores de tal modo que la casilla de la esquina situada a la derecha de cada uno de ellos sea blanca. (Lucila, 1998) materiales

Material. Las piezas de Ajedrez deberán ser de madera, plástico o una imitación de estos

Altura, peso, proporciones. La altura del Rey deberá ser de 8.5 a $10.5 \mathrm{~cm}$. El diámetro de la base del Rey debe medir de 40 a $50 \%$ la medida de su altura. 
La medida de las otras piezas deberán estar en proporción a su altura y forma; otros elementos tal como estabilidad, consideraciones estéticas, etc. también deben ser tomados en cuenta.

El peso de las piezas deberá ser adecuado para una estabilidad y movimiento confortable.

Tableros. Madera, cartón o tela son recomendados como material para los tableros de Ajedrez.

El tablero también puede ser de piedra o mármol con colores apropiados claros y oscuros, siempre y cuando el árbitro oficial lo encuentre aceptable. Madera natural con un contraste suficiente tal como abedul, arce o fresno Europeo en contra de nogal, teca, haya, etc., puede también ser usada para los tableros la cual deberá tener un acabado opaco o neutral, nunca brillosa. Una combinación tal como café, verde, o un marrón muy claro y blanco, crema, marfil blancuzco, ante, etc. puede ser usado para las casillas de Ajedrez en adición a los colores naturales.

El tamaño del tablero deberá ser de tal manera que las piezas de Ajedrez no se vean muy amontonadas ni tampoco demasiado espaciadas dentro de las casillas. Se recomienda que un lado de una casilla debe medir de $5 \mathrm{~cm}$. a $61 / 2 \mathrm{~cm}$. En el siguiente cuadro se detalla lo mencionado partiendo del estudio de la iconografía del Ecuador realizado por la fundación Sinchi Sacha y el Museo Etnohistórico Mindalae que en su Manual iconográfico describe significados e interpretaciones iconográficas de algunos vestigios incluidos en él.

\begin{tabular}{|c|c|c|c|c|c|}
\hline AJEDREZ CONTEMPORANEO & \multicolumn{5}{|c|}{ AJEDREZ (ICONOGRAFIA DE CULTURAS ECLATORIANAS) } \\
\hline ASIGNACION CONNOTACIDN & ICONOGRAFIA & SIGNIFICADO & MA'ERIAL & VALOR & DIMENSION \\
\hline soldado & & $\begin{array}{l}\text { El guerrero: } \\
\text { La fusión del furor murcielago con la } \\
\text { astucia del zorro perfeccionar al guerrero } \\
\text { y lo praparan para la batalla }\end{array}$ & madera & $1 \mathrm{pt}$ & $4 \mathrm{~cm}$ \\
\hline
\end{tabular}




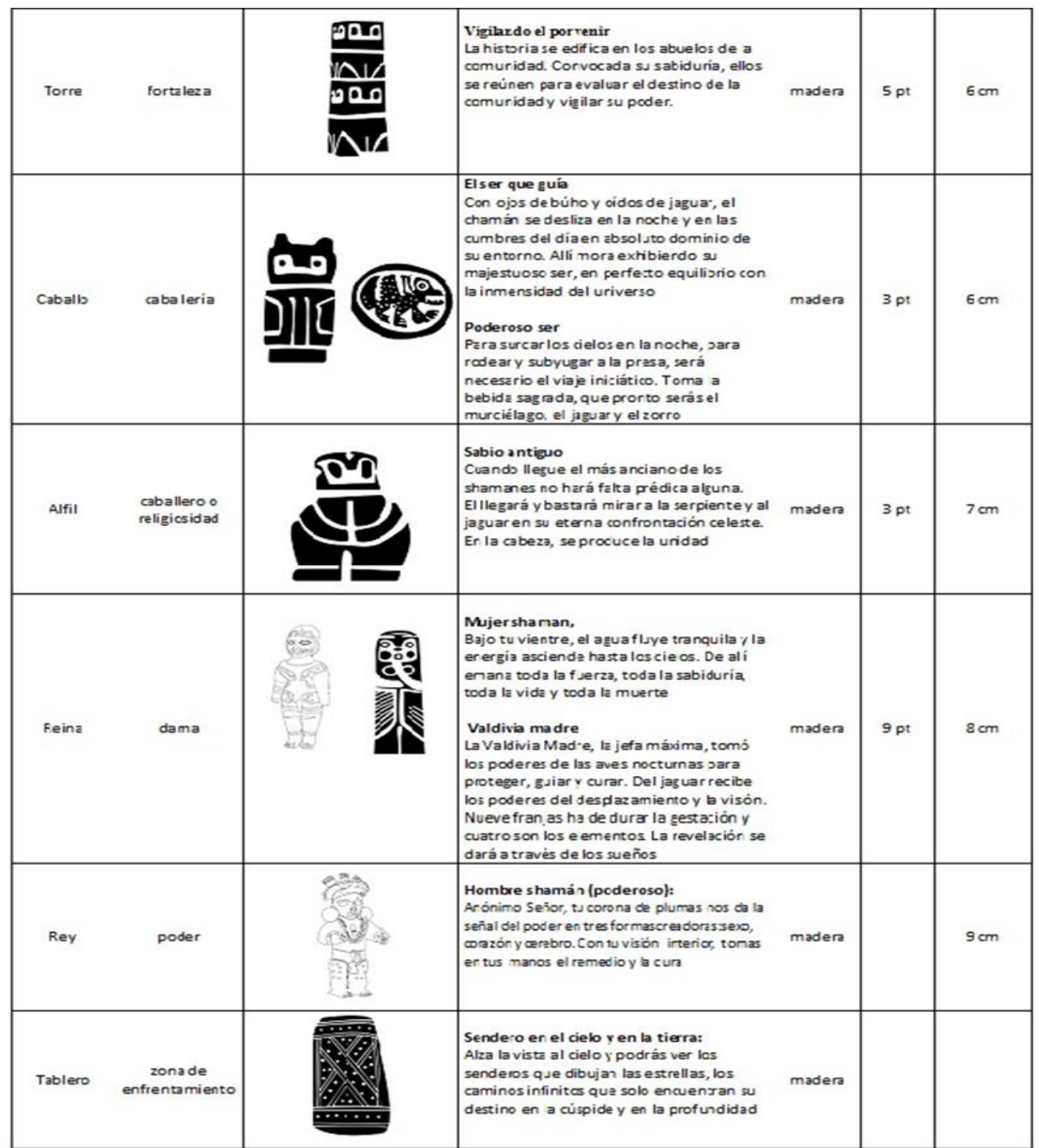

Figura Nro.5: Asignación de valores a figuras de ajedrez ancestral, simbología MIMDALAE. Elaboraron: Estudiantes del Ciparq UIDE. Teoría de la Arquitectura 2

En el caso del documento de la fundación Sinchi Sacha vemos que los símbolos y sus textos poéticos pertenecen a los territorios culturales Manta - Huancavilca, la Tolica, Jama Coaque y Pasto. Cada uno tiene la datación correspondiente.

La simbología se clasifica en 4 grupos:

1. Cosmogonía

2. Sabiduría

3. Sociedad y naturaleza

4. Genero

Se menciona en su descripción, que en el pasado remoto, los habitantes del Ecuador elaboraron sistemas singulares de organización de sus comunidades y modelos de vida que se fueron edificando con el tiempo y las aguas. En las aldeas dispersas y sus rutinas cotidianas, en 
el recorrido sinuoso de sus senderos, en los temblores de los volcanes, en la domesticación de las plantas y de los animales, en las exploraciones marinas, en los páramos del placer y del dolor, en las misiones suicidas y salvadoras hacia la selva amazónica y viceversa, en los parajes estremecedores de las nieves eternas, pero sobre todo en los viajes cósmicos, estos abuelos antiquísimos elaboraron un complejo universo de símbolos que atraen con el temblor del asombro y de la fascinación. Pero se trata de unos significantes casi inagotables, que además tienen el rastro histórico de ser huidizos e intrépidos, especialmente en sus significados, cuya polisemia nos deja absortos frente a los enigmas del pasado. Por todo esto y más, nosotros preferimos edificar una estela de continuidad desde el shamanismo, con la intención de buscar unas interpretaciones signadas por la palabra, por la poesía y por este deseo inocultable de sumergirnos en su océano simbólico, paradójicamente lleno de futuro (Sacha, s.f.)

En la misma línea y siguiendo la metodología presentada por el Mindalae, el proceso de diseño seguirá 3 fases:

Fase 1: Identificación de la iconografía de los pueblos originarios, reconocimiento de los lugares donde éstas se encontraron, para luego realizar la geometrización de éstas.

Fase 2: Se analizará la semiótica de estos signos, describiendo el concepto de las formas usadas en cada signo, finalmente se intentará realizar un vocabulario visual de los pueblos originarios considerados. Una de las partes fundamentales de esta fase es la creación de patrones gráficos.

Fase 3: En esta fase se realizará el proceso creativo de diseño, para lo cual nos basaremos en los patrones gráficos obtenidos en la fase 2 de la investigación. En este punto, diseñaremos productos para la producción artesanal, que tenga como objetivo posterior la producción semi industrial. Se establecerán normas de calidad para el proceso de producción por categorías, para que después se proceda ya con la producción y comercialización en al menos una de las categorías.

El diseño es un proceso de creación visual con un propósito, o la mejor expresión visual de algo ya sea esto un mensaje o un producto donde el diseñador debe buscar la mejor forma posible para que se algo sea conformado, fabricado, distribuido, usado y relacionado con su ambiente. (Wong, 2011).

La identidad es la síntesis que cada uno hace de los valores y de los indicadores de comportamientos transmitidos por los diferentes medios a los que pertenece. Integra esos valores y esas prescripciones según sus características individuales y su propia trayectoria de vida. La identidad es considerada como un fenómeno subjetivo, de elaboración personal, que se construye simbólicamente en interacción con otros. La identidad personal también va ligada a un sentido de pertenencia a distintos grupos socio- culturales con los que consideramos que compartimos características en común.

\section{Análisis Semiótico, Realización De Un Vocabulario Visual, Creación De Patrones Gráficos, Geometrización (Fase 2).}


Se realiza un análisis previo de cada simbología, teniendo en cuenta su representación simbólica y valoración dentro de la cultura que se encuentran. En la Figura Nro. 5, vemos como se parte desde una descripción iconográfica clara, tomando algunos de los símbolos que tengan relación, con cada una de las piezas del ajedrez; valoración, movimientos, connotación. A continuación se realizan bocetos buscando la geometrización de ciertas formas a utilizar en el diseño de cada una de las piezas del ajedrez:

\section{El Peón.}

La fusión del furor murciélago con la astucia del zorro perfecciona al guerrero y lo preparan para la batalla.

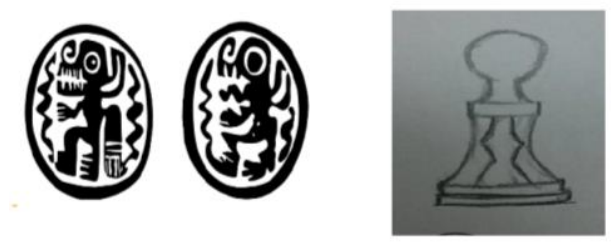

Torre.

La historia se edifica en los abuelos de la comunidad. Convocada su sabiduría, ellos se reúnen para evaluar el destino de la comunidad y vigilar su poder.

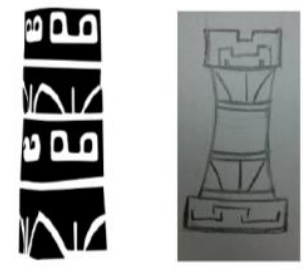

\section{Caballo - Búho.}

Con ojos de búho y oídos de jaguar, el chamán se desliza en la noche y en las cumbres del día en absoluto dominio de su entorno. Allí mora exhibiendo su majestuoso ser, en perfecto equilibrio con la inmensidad del universo

Para surcar los cielos en la noche, para rodear y subyugar a la presa, será necesario el viaje iniciático. Toma la bebida sagrada, que pronto serás el murciélago, el jaguar y el zorro

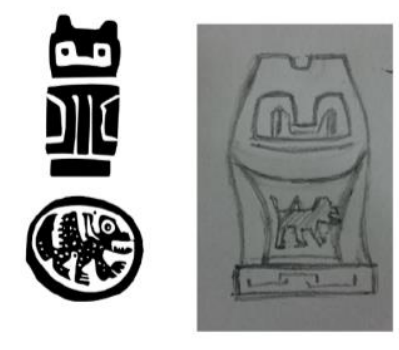

Alfil.

Cuando llegue el más anciano de los shamanes no hará falta prédica alguna el llegará y bastará mirar a la serpiente y al jaguar en su eterna confrontación celeste. En la cabeza, se produce la unidad. 


\section{Reina.}

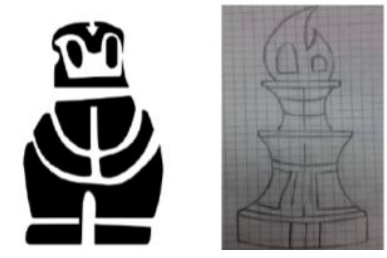

Bajo tu vientre, el agua fluye tranquila y la energía asciende hasta los cielos. De allí emana toda la fuerza, toda la sabiduría, toda la vida y toda la muerte

La Valdivia Madre, la jefa máxima, tomó los poderes de las aves nocturnas para proteger, guiar y curar. Del jaguar recibe los poderes del desplazamiento y la visión. Nueve franjas han de durar la gestación y cuatro son los elementos. La revelación se dará a través de los sueños.
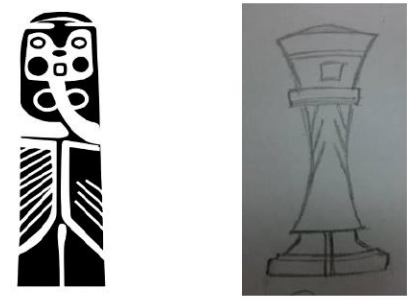

Rey.

Anónimo Señor, tu corona de plumas nos da la señal del poder en tres formas creadoras: sexo, corazón y cerebro. Con tu visión interior, tomas en tus manos el remedio y la cura.
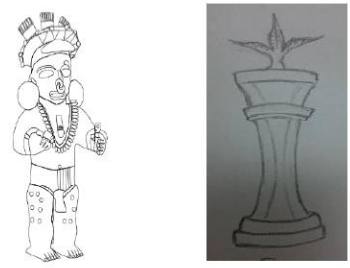

\section{Simbología Palta}

La simbología de las paltas representa un análisis de ciertos elementos característicos de la cultura, tal como sus antepasados, astrología, fenómenos naturales y varias representaciones simbólicas. 


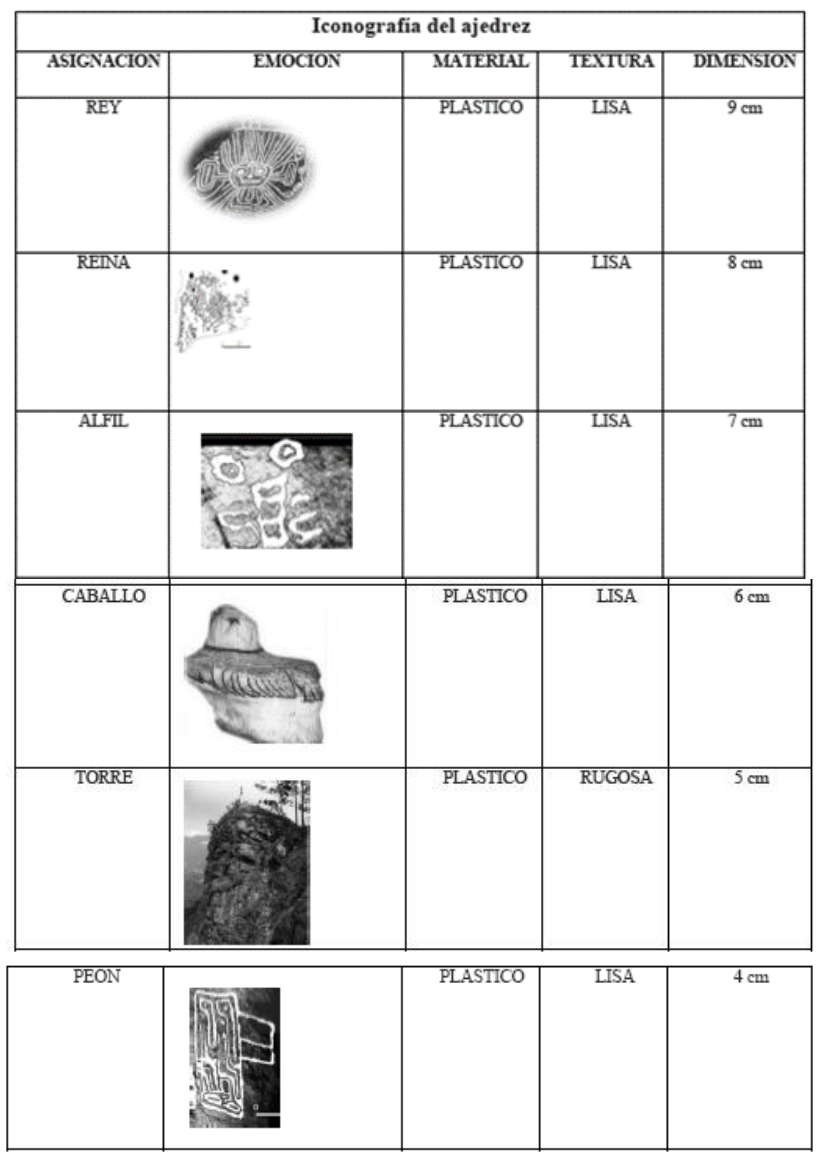

Figura Nro.6: Asignación de valores a figuras de ajedrez ancestral, simbología PALTA .Elaboraron: Estudiantes del Ciparq UIDE. Teoría de la Arquitectura 2

En la experiencia docente se plantea en el proceso de enseñanza aprendizaje el ciclo de abstracción y geometrización como una búsqueda de diseño contemporáneo, sin buscar la realización de réplicas del patrimonio cultural, sino más bien de reinterpretar conceptos originarios.
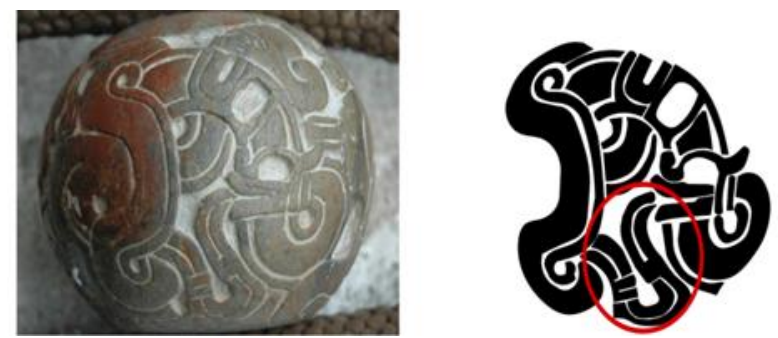

Figura Nro.7: Patrón Gráfico extraído de un vestigio Palta. Fuente: (Herrera, 2015)

La Arq. Mayra Herrera Jaramillo, con su trabajo de investigación de la UIDE, se ubicó en el componente de saberes ancestrales entre los 9 mejores proyectos nacionales del "II Concurso De Reconocimiento A La Investigación Universitaria Estudiantil: Galardones Nacionales 2014" de la SENESCYT, menciona sobre la Figura Nro. 7, que se trata de una Caja de llipta de piedra, procedente del cerro Trapichillo, y que probablemente haya sido parte de una ofrenda hecha en la huaca de Trapichillo, posee una decoración grabada que recuerda al estilo de la cultura Chavín 
(900 aC- $200 \mathrm{aC}$ ). Se extrae un patrón gráfico que será geometrizado de manera propia y aplicada en un producto utilitario, como un souvenir tal como se observa en la Fig. Nro. 8.

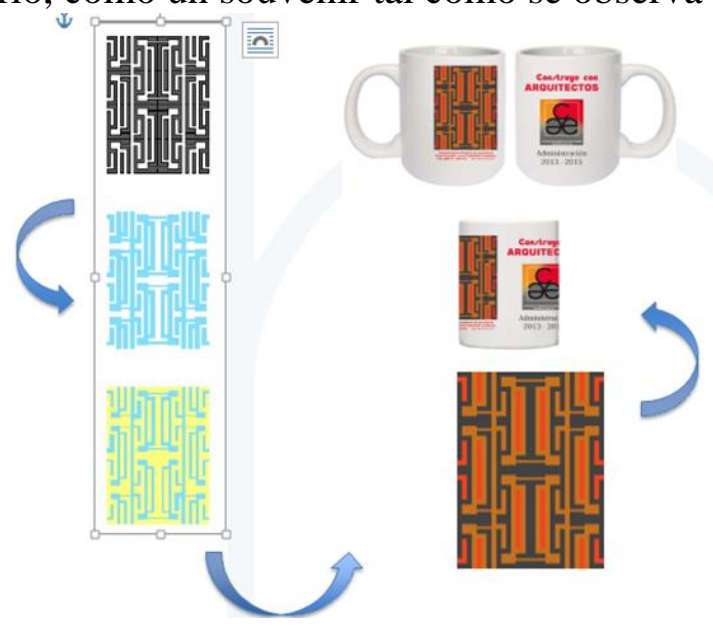

Figura Nro.8: Evolución del Patrón Gráfico hacia el diseño de un souvenir. Fuente: El Autor, souvenir del Colegio de Arquitectos de Loja

\section{Diseño De Productos Para La Producción Artesanal (Fase 3).}

En esta fase se realiza el proceso creativo de diseño aplicado, para lo cual nos basaremos en los patrones gráficos obtenidos en las fases anteriores. En este punto, diseñaremos productos para la producción artesanal.
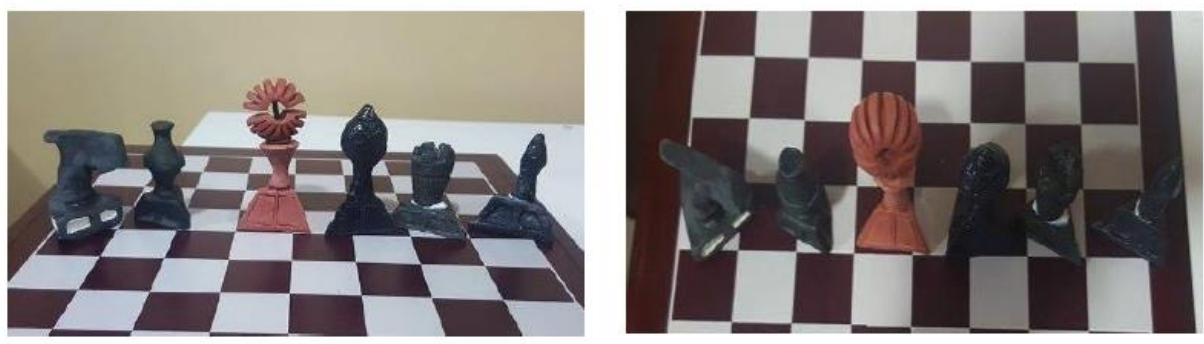

Figura Nro.9: Prototipo modelado manual de AJEDREZ PALTA. Diseño: Estudiantes del Ciparq UIDE. Teoría de la Arquitectura 2

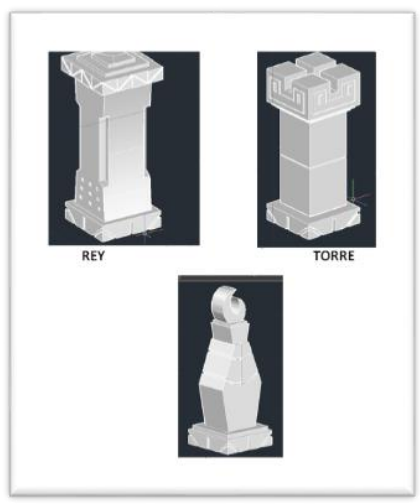

Figura Nro.10: Prototipo digital de AJEDREZ MINDALAE Diseño: Estudiantes del Ciparq UIDE. Teoría de la Arquitectura 2 

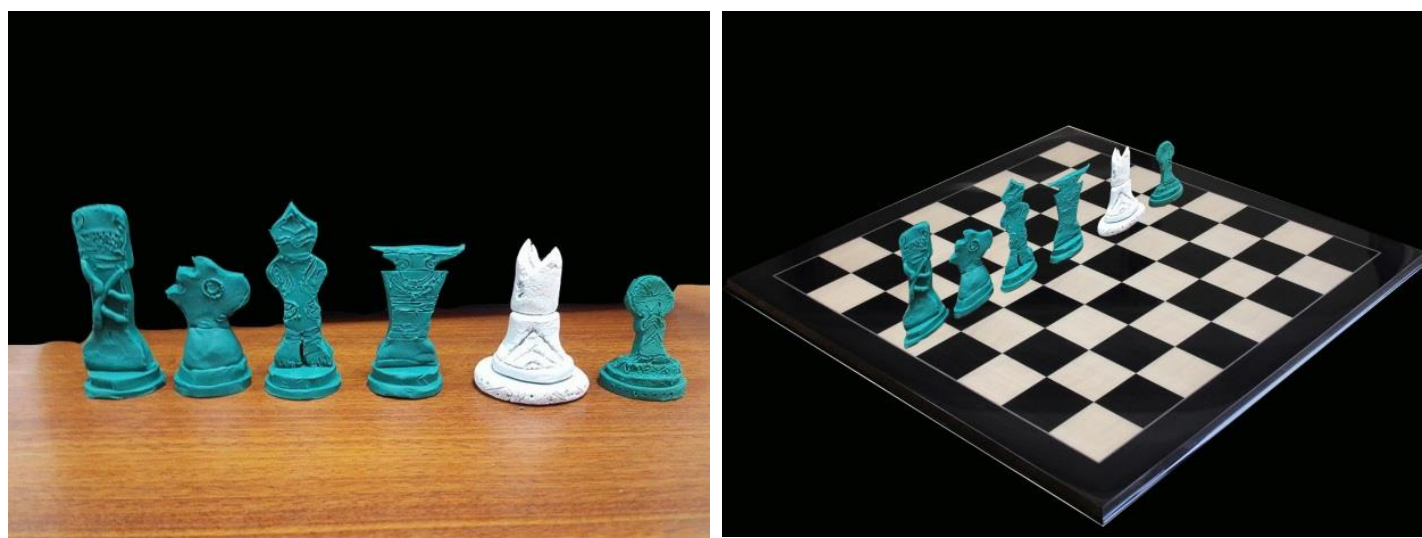

Figura Nro.11: Prototipo modelado manual de AJEDREZ MINDALAE 2. Diseño: Estudiantes del Ciparq UIDE. Teoría de la Arquitectura 2

De igual manera, en el mismo proceso se aplica la metodología a diferentes elementos de diseño utilitario, en diferentes soportes como vemos en la Figura Nro. 10.
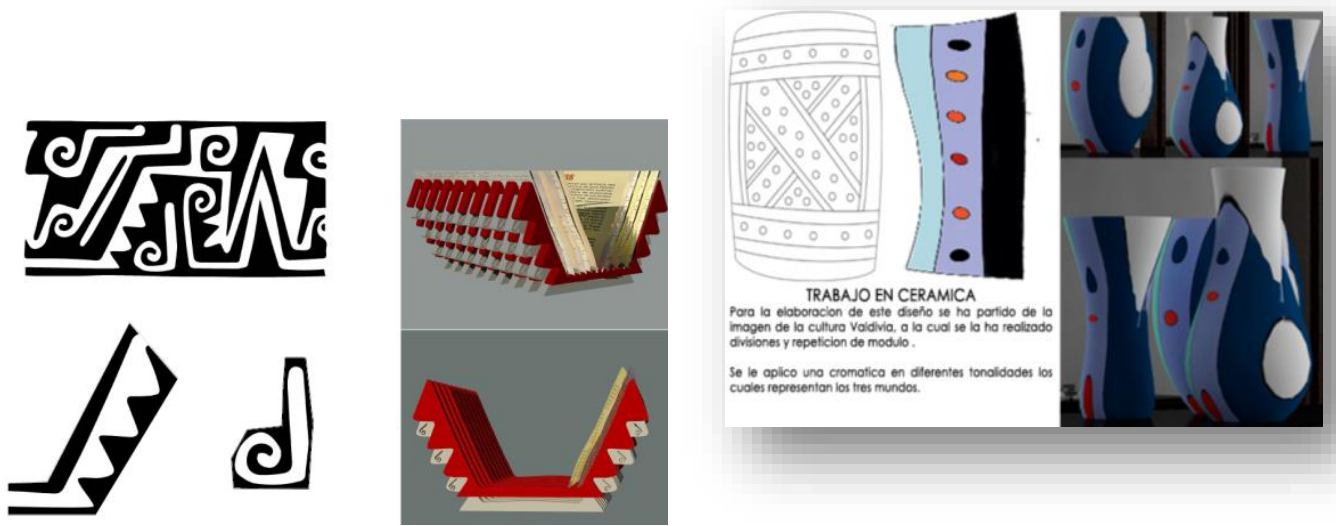

Figura Nro.12: Diseños HOMEDECO con identidad. Diseño: Estudiantes del Ciparq UIDE

\section{Validación Del Mercado O Cliente.}

Desde este momento, debemos contrastar además la percepción del diseñador, con las herramientas Javelin del Centro de Emprendimiento Prendho, específicamente en el segmento Souvenirs Con Identidad.

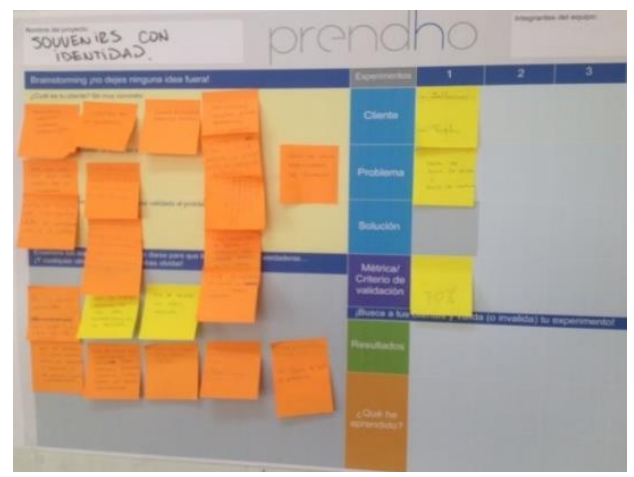


Figura Nro.13: Tablero JAVELIN souvenirs con identidad. Fuente: Arqandes, PRENDHO, estudiantes del Ciparq UIDE

Se hace uso de esta metodología para saber si la acogida de la idea de utilizar la iconografía ancestral procedente de Loja como diseño de souvenirs con identidad tiene aceptación, se realizaron entrevistas informales a turistas y a funcionarios de instituciones públicas y privadas con la modalidad "escuchar al cliente". Para que el emprendimiento de resultados positivos debería tener una acogida del mercado de un $70 \%$ (validación). clientes:

Se realizaron dos preguntas importantes en una conversación informal con los posibles

1ra Pregunta: ¿Cuál crees que sería un obsequio adecuado para llevar a una persona que no conozca Loja que sea propio de esta ciudad y que la caracterice como tal?

\begin{tabular}{|c|c|c|}
\hline Respuestas & Porcentaje \% & Valor \\
\hline $\begin{array}{l}\text { Figuas de la torre de San } \\
\text { Sebastian y las iglesias en } \\
\text { llaveros }\end{array}$ & $30 \%$ & Entre 1,50 y 2,00 usd \\
\hline $\begin{array}{l}\text { Gravado en vidrio y madera de la } \\
\text { puerta de la cuidad }\end{array}$ & $20 \%$ & Entre 6,00 y 10,00 usi. \\
\hline $\begin{array}{l}\text { Cajas de madera con gravados de } \\
\text { las igle sias y la tore de S.S. }\end{array}$ & $40 \%$ & Entre 10,00 y 15,00 usd. \\
\hline $\begin{array}{l}\text { Bufandas, gonros de lana y } \\
\text { camise tas }\end{array}$ & $40 \%$ & Entre 2,00 y 6,00 usd \\
\hline $\begin{array}{l}\text { Vasos con fragmentos de } \\
\text { escritores lojanos }\end{array}$ & $10 \%$ & Entre 3,00 y $6, \infty$ uscl \\
\hline $\begin{array}{l}\text { Jarros y platos con la imagen de } \\
\text { la puerta ce la ciuclad }\end{array}$ & $30 \%$ & Entre 5,00 y 10,00 usd. \\
\hline Moc Chlas con diseños & $20 \%$ & Entre 10,00 y 15,00 uscl \\
\hline
\end{tabular}

Figura Nro.14: Respuestas a pregunta 1 de turistas. Elaborado: Arqandes, PRENDHO, estudiantes del Ciparq UIDE

2da Pregunta: ¿Estarías dispuesto a comprar un objeto con motivos iconográficos ancestrales característicos de Loja? En la respuesta sólo se recibió una respuesta positiva del $30 \%$ de los entrevistados.

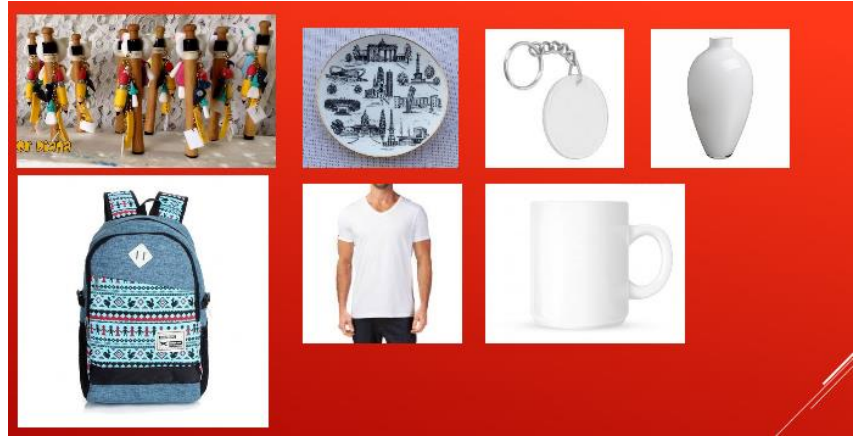

Figura Nro.15: Ideas de souvenirs requeridos por turistas en Loja. Elaborado: Arqandes, PRENDHO, estudiantes del Ciparq UIDE

En el otro segmento de mercado y clientes priorizado en el tablero Javelin, se consideran las instituciones de Loja. De 4 de ellas se valida en este caso con un $75 \%$ las mismas preguntas realizadas al segmento anterior. De las sugerencias planeadas en souvenirs específicos a producirse para ellos, tenemos: Botellas con motivos de la ciudad. La imagen del teatro nuevo de Loja y del teatro Simón Bolívar. EL reloj de San Sebastián.La imagen de la institución. Los símbolos encontrados en las ruinas de ciudadela y lugares arqueológicos de San Lucas. 


\section{Conclusiones Del Javelin:}

- Para poder generar el emprendimiento de los souvenirs con identidad lojana lo primero que se debe hacer es concientizar a la ciudadanía sobre la importancia de rescatar nuestras raíces ancestrales y generar un sentimiento de apropiación.

- Mientras no haya interés por parte de la mayoría de personas el proyecto será bien visto solo por conocedores del tema.

- La validación se da sólo en el caso de las instituciones con un 75\%, versus la percepción de los turistas que prefieren otros motivos o íconos simbólicos ya posicionados en Loja.

- La conclusión más importante se refiere a replantear el producto, y dotar de valores agregados a las piezas de diseño como por ejemplo generar una plataforma tecnológica en la Web en donde se ubiquen los lugares de origen y vestigios que sirven de inicio del proceso, para determinar una marca de origen.

A continuación se adjuntan imágenes de algunos prototipos en esa línea:
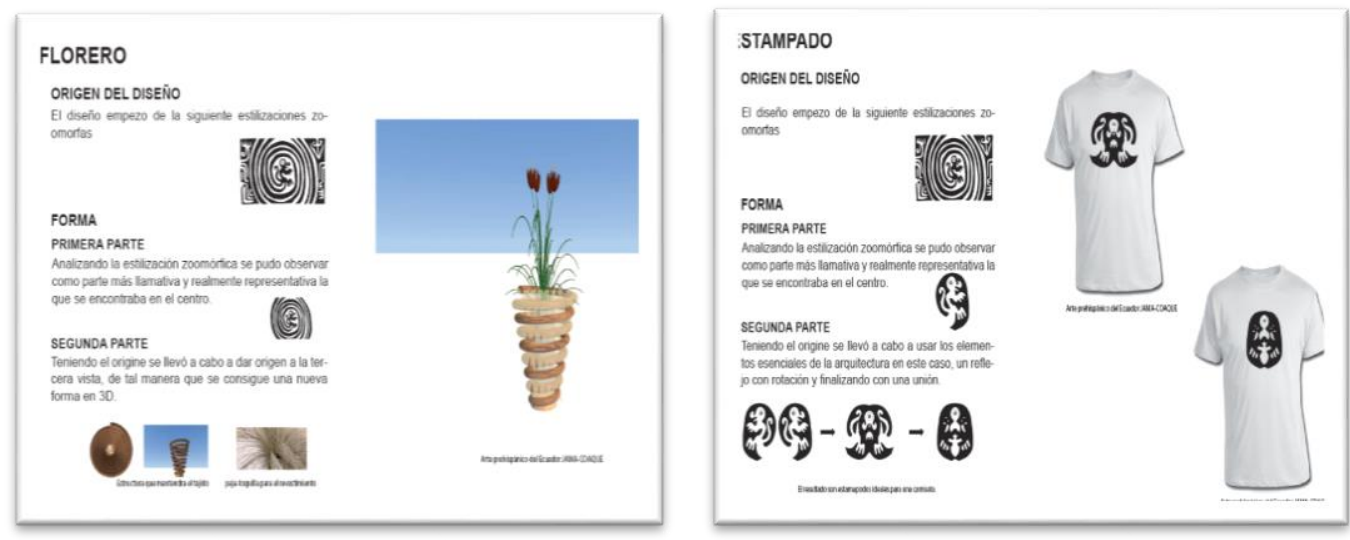

Figura Nro.15: Diseños de souvenirs con identidad en madera y textiles. Diseño: Estudiantes del Ciparq UIDE
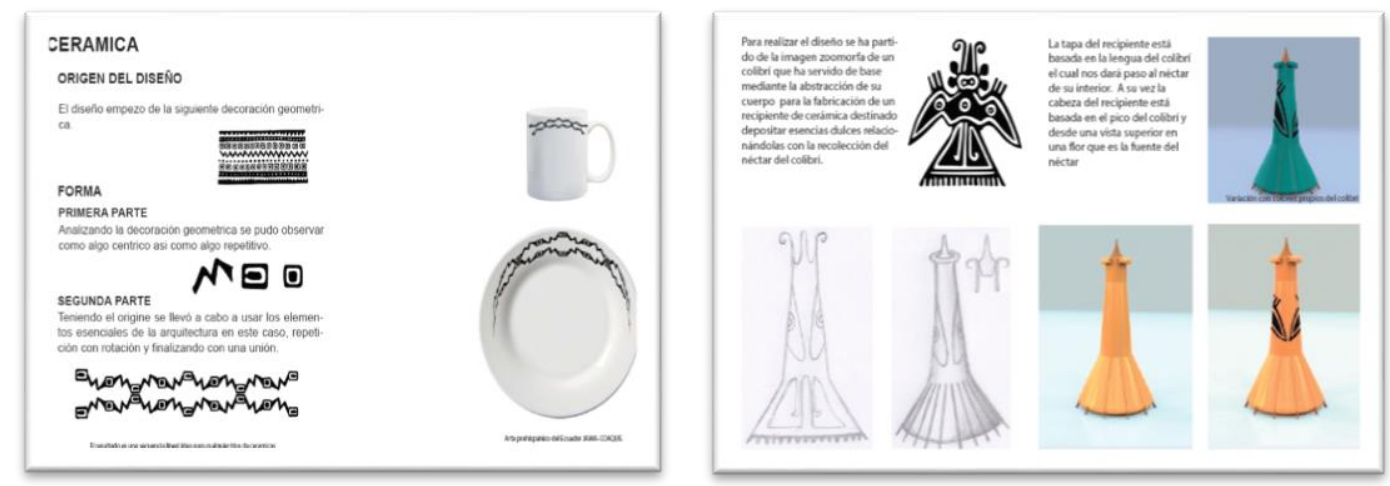

Figura Nro.16: Diseños de souvenirs con identidad en cerámica. Diseño: Estudiantes del Ciparq UIDE

De dichos productos se establecerán normas de calidad para el proceso de producción en las categorías antes referidas, para que después de terminada la investigación se proceda ya con la producción y comercialización en al menos la mitad de las categorías mencionadas, de inicio. Producción y comercialización es la etapa final del proyecto. En esta fase, es importante 
mencionar la necesidad de incorporar el I+D de las universidades a través de sus estudiantes por un lado y por otro lado la posibilidad de trasferir las experiencias de cada parte éxitos del proceso, hacia la comunidad, como planteábamos el inicio del presente trabajo, hacia los artesanos y diseñadores de la provincia de Loja para conseguir una correlación en dos vías de aprendizaje mutuo.
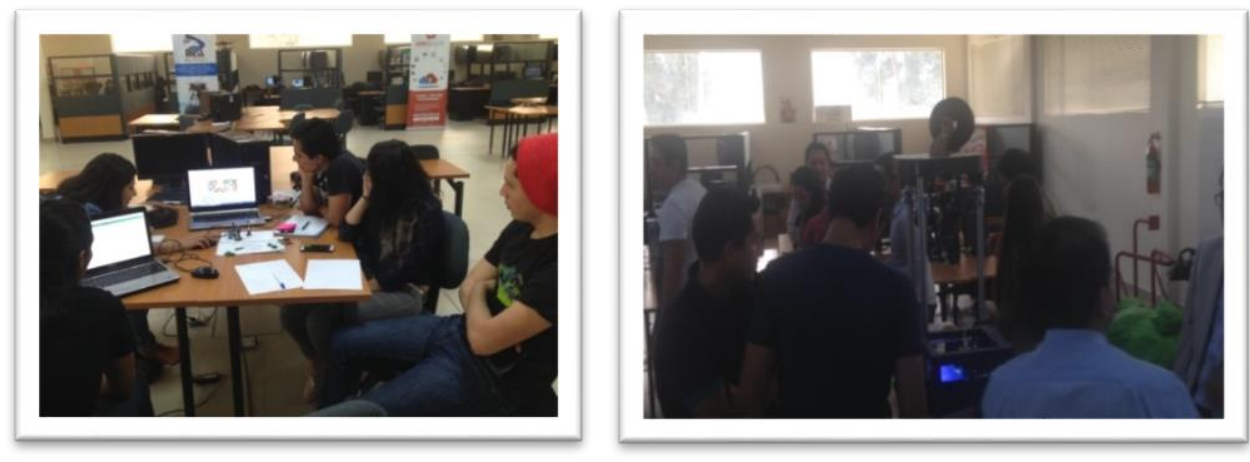

Figura Nro.17: Estudiantes del Ciparq UIDE desarrollando su emprendimiento, impresora 3D en fase de fabricación Lugar: Centro de emprendimiento Prendho
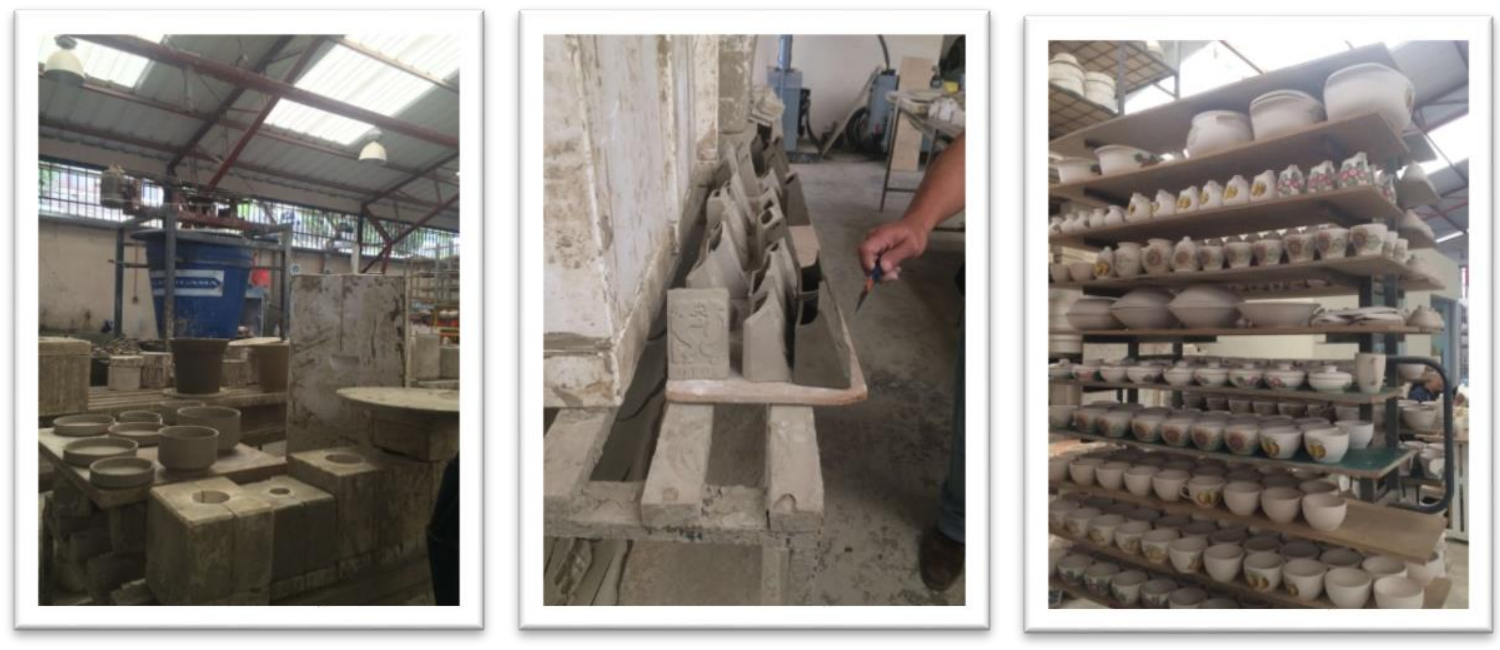

Figura Nro.18: Planta de cerámica de la UTPL, potencial aporte al desarrollo de emprendimientos de diseño y trasferencia a artesanos lojanos. Fuente: El autor

\section{Agradecimientos}

- Universidad Internacional del Ecuador, Extensión de Loja

- Escuela de Arquitectura cipArq

- Centro de Emprendimiento PRENDHO

- Arqandes

- Fundación Sinchi Sacha

- Estudiantes del Ciparq UIDE. Teoría de la Arquitectura 2:

Aguirre María Rosa, Bejarano Ortega Lisbeth, Burneo Pachar Jamil Andrés, Cango Jimena, Castillo Michelle, Conza Byron, Guerrero Tatiana, Guzmán Christian, Hernández 
Alfredo, Hurtado Jessica, Ruth Carrión Anthony Michael, Ruth Carrión Herman Oscar, Jiménez Joffre, Jiménez Marco, León Jairo, López Yunga Junior Stalin, Luzuriaga Andrés, Maldonado Josué, Quevedo Josué, Medina Darío, Ramírez Jackson, Ruiz Carrillo Cristian Alexander, Zuñiga Gabriela.

\section{Bibliografía}

Herrera, M. (2015). Investigación iconográfica e histórica de los pueblos originarios del valle de Catamayo para la aplicación en el diseño y el arte. ASRI Revista Investigación Arte Y Sociedad.

Hora, D. L. (27 de 08 de 2014). La Hora, Lo que necesitas saber. Recuperado el 18 de 09 de 2016, de http://lahora.com.ec/index.php/noticias/show/1101718801/1/home/goRegional/Manabi\#.V97nKvnhDbg

Panofsky, E. (1939). Estudios sobre iconología.

Peltzer Gonzalo. (s.f.). Periodismo Iconográfico. Recuperado el 19 de Julio de 2016, de https://books.google.es/books?hl=es\&lr\&id=J1Stue0UntcC\&oi=fnd\&pg=PA15\&dq=icon ografia\%20para\%20el\%20dise\%C3\%B1o\&ots=g6k1homtCB\&sig=BIVpuNM3HXNX9u Q6IDrkmDVXQxg\#v=onepage \&q\&f=false

Rodríguez López Martha Isabel. (2005). Introducción General a los estudios Iconográficos y a su Metodología. Recuperado el 20 de Julio de 2016, de http://pendientedemigracion.ucm.es/centros/cont/descargas/documento4795.pdf

Lucila, M. (1998). Monografias.com. Recuperado el 23 de Julio de 2016, de El Ajedrez: http://www.monografias.com/trabajos61/ajedrez/ajedrez.shtml

Sacha, F. S. (s.f.). Mindalae museo etnohistórico de artesanías del Ecuador. Obtenido de http://www.mindalae.com.ec/index.php/introduccion-introduccion-ipf

Wong, W. (2011). Fundamentos del diseño. Barcelona: Gustavo Gili.

Navarrete, S. Fenomenología. Una alternativa de investigación científica, más próxima al diseño.

Merleau-Ponty, M. (1975). Fenomenología de la percepción (p. 475). Barcelona: Península.

Visoná, P., \& Palmitessa, G. (2014). Metodologías del diseño en la promoción de aprendizaje organizacional. Cuadernos del Centro de Estudios en Diseño y Comunicación. Ensayos, (49), 143-157.

Montaño. L. aprender a pensar. Obtenido de método fenomenológico: http://lorefilosofia.aprenderapensar.net/2011/10/08/metodo-fenomenologico/

Loreto, R. G., \& Toranzo, F. M. (2003). Un nuevo lenguaje en la red. Comunicar: Revista científica iberoamericana de comunicación y educación, (21), 133-136. 